\title{
Driver distraction and the role of cognitive and visual abilities for Road Safety Practices
}

\author{
S.Keffane \\ PhD in Psychology, Researcher, Department of Psychology, University Setif 2, Setif, Algeria. \\ Corresponding author: S.kefane (E-mail: keffane1967@yahoo.fr)
}

Keywords: Driver distraction, Cognitive Vision abilities, Driving experience, Safety driving, Road Safety Practices.

\begin{abstract}
Driver distraction represents a significant problem in a motor vehicle is a complex activity. This study exist for evaluated part of the Multifactorial Model of distraction, Driving Safety to elucidate the relative importance of cognitive function and measures of visual function in the capacity to Drive Safely. This article investigates the nature of driver distraction at a major Algerian a motor vehicle. At present, increasing amounts of visual information from sources such as roadside advertising create visual clutter in the road environment, including the sources of distraction present, and their effects on driver performance, cognitive and visual function (CV) capacity supports goal-directedness which minimizes the influence of distracting stimuli in favor of driving-relevant stimuli. Cognitive and visual function (CV) capacity can be discriminated and are both addressed during driving. This study investigated for driving experience $(\mathrm{n}=$ 300 , age $=18-25$ ), These included an adaptation of the well validated Useful Field of View (UFOV) and two newer measures, namely a Hazard Perception Test (HPT), and a Hazard Change Detection Task (HCDT).
\end{abstract}

The Capacity to Drive Safety is associated with several higher order cognitive abilities involving manipulation and storage of visual spatial information under speeded conditions. There are also the effects of cognitive function and vision that determine driving safety.

\section{Introduction}

The concept of driver distraction has been the focus of intense research attention. Driver distraction is now widely recognized as a significant road safety issue “[1], [2]”. Driver distraction and driver error are two currently popular concepts within road safety research “[3], [4]”. The findings from the '100-Car Naturalistic Driving Study' identified distraction as a contributory factor in around 23 percent of crashes and near crashes [5]. Moreover, these degradations have also been shown to translate into an increased risk of crash involvement, with estimates indicating that secondary task distraction is a contributing factor in up to $23 \%$ of crashes and near-crashes [5]. In addition, a range of studies have observed that distracted drivers demonstrate degraded performance on a number of safety critical driving measures, including impairments in longitudinal "[6], [7]” and lateral control “[8], [9]”; a reduced awareness of surrounding traffic and events [10]; an increased tendency to miss 
traffic signals and signs and increased response time to roadway events "[11], [12]”, and a reduction in time spent checking instruments and mirrors [13]. Although the two phenomena are ostensibly related to one another, there has been little exploration of how they are related and what the effects of one are on the other. Visual function and cognition are two key components of the Multifactorial Model of Driving Safety [14]. In this model they are intercorrelated, and both predict the Capacity to Drive Safely.

The Capacity to Drive Safely, in conjunction with other factors such as self-monitoring [15]. And beliefs about one's driving competence under varying conditions [16], is argued to predict actual driving behavior. Off-road driver screening tests are measures of the Capacity to Drive Safely whereas 'on-road' driving measures assess actual 'driving behavior'. The present study focuses on elucidating the nature of the relationship between cognitive and visual abilities in relation to the Capacity to Drive Safely.

At present, several questions remain unanswered regarding the relative role of visual and cognitive function in predicting driving safety. While visual testing is mandatory in many jurisdictions [17], Understanding how cognitive and visual ageing affect performance on instruments designed to predict driving skills in late life will not only assist in improving the design of these measures, but will also indicate whether specific screening instruments are more suitable for different sub-populations, in the same way that a neuropsychological test battery would be designed differently for different populations. Moreover, accurate theoretical models of the interrelationships between sensory and cognitive function are required for the development of effective interventions to improve driving safety, such as tailored cognitive training programs “[18], [19], [20]”, and effective management and treatment of eye disease. Such training studies have been undertaken with driver screening instruments as the outcome measure because they are safer, cheaper, and potentially more reliable and valid (e.g. extreme crash situations can be presented at a high frequency and in a more standardized manner) than on-road driving tests [21].

Our aim in this study was examining the 'Capacity To Drive Safely' via inclusion of three validated screening measures that have been linked to self-reported crashes or unsafe on-road driving performance. These are an adaptation of the Useful Field of View (UFOV), a Hazard Perception Test (HPT) and a Hazard Change Detection Test (HCDT). The most commonly investigated cognitive functions have included attention, processing speed, executive functioning, visuo-spatial skills, vision, and mental status; and several tests based on these abilities have been proposed as predictors of safe driving ability. One of the most successful fitness to drive tests is the Useful Field of View (UFOV) test [22]. UFOV performance has been shown to predict retrospective and prospective crash involvement, on-road driving performance, and driving simulator performance “[23], [24], [25]". The UFOV test involves detection, localization, and identification of stimuli located throughout the visual field and comprises three subtests of increasing difficulty that require identification of a central stimulus and localization of a peripheral stimulus under different conditions [26]. All subtests involve visual processing under limited time, justifying the conclusion that UFOV measures "an individual's speed of processing across increasingly complex visual displays" [26].

Ball and colleagues have proposed that UFOV performance reflects the ability to rapidly scan the visual field and focus on salient features and that this in turn depends on speed of visual processing, divided attention, and selective attention “[27], [28]". UFOV has undergone only limited psychometric evaluation, and theories of visual attention have changed substantially since the test was first developed “[29], [30]”. [31] Have suggested that poor UFOV performance may be caused by deficits in intentional control processes, specifically reduced intentional disengagement (the ability to shift the focus of attention rapidly when required to do so), rather than a reduction in "intentional breadth"; i.e. the area in the visual field that can be searched within a single fixation. It's 
also possible that UFOV primarily reflects speed of information processing [32].

[33] developed a visual change detection task(Drivers can) for older adults based on the 'flicker' paradigm where a blank screen in displayed between an image and an altered version of that image, thereby masking luminance cues to the location of the change [34]. Rapid detection of change under these conditions requires focused attention to the area being changed “[34], [35]”.

[36] Investigated the contribution of a battery of cognitive and visual tests to UFOV and two other tests of safe driving capacity: a hazard perception test and a change detection test. Factor analysis on the battery of tests revealed five factors: executive/speed, vision, spatial ability, visual closure, and working memory. Their results showed that UFOV performance was significantly related to the executive/speed, spatial ability, and working memory factors. Cognitive and visual factors together accounted for $40 \%$ of the variance in UFOV performance, $44 \%$ of variance in change detection performance, and $30 \%$ of variance in hazard perception performance. Hazard perception Test (HPT) is the capacity of drivers to identify and respond to dangerous situations [37].

It involves a number of processes, including detection of a potential hazard, appraisal of the hazard as a threat followed by selecting and implementing an appropriate response [38]. [39] Argue that the critical aspect of hazard perception is processing the visual scene. Video-based hazard perception tests have been developed to mimic traffic situations where crashes are most likely to occur and are now mandatory aspects of licensing tests for new drivers in some jurisdictions. Hazard Change Detection Test (HCDT), detection of change often described as change blindness, is a failure to notice changes made to an object or a scene during a saccade, flicker, blink, or movie cut [40]. Researchers have shown that change blindness occurs in response to a range of stimuli including photographs, computer-generated natural scenes, artificial displays, motion pictures, and even people during interpersonal interactions [35]. Specifically, the inability of drivers to effectively detect changes in a dynamic environment, such as a busy intersection, may correspond to an important visual attention failure [41]. Older adults have also been shown to be slower than younger adults to perceive changes to photographs of driving scenes [42]. Hazard Change Detection Test [43] used in this study takes advantage of this phenomenon by measuring how long drivers take to identify a hazard (that repeatedly appears and disappears) in an image of a traffic scene, taken as an indication of their ability to detect dangerous elements in the road environment. It has not been validated against an on-road driving assessment but has been shown to correlate with hazard detection ability in older drivers [43].

Our aim in this study was to determine whether the cognitive and visual abilities to predictors explained variance in the driver distraction and capacity to drive safely. Similarly we estimated the extent to which cognitive and visual factors and measures of the capacity to drive Safety.

\subsection{Driver Distraction.}

Driver distraction is acknowledged internationally as a significant road safety concern [2]. Sources of distraction can either derive from within the vehicle (e.g., a passenger, technology) or from outside the vehicle (e.g., roadway advertisement, pedestrians). Distraction can also take a number of distinct, but not mutually exclusive, forms; including visual, cognitive, auditory and bio-mechanical distraction, some of which have been shown to have diverse effects on driving performance "[44], [8]". Although many definitions exist, driver distraction is conceptualized by [45] as a diversion of attention away from activities critical for safe driving towards a competing activity. Researchers typically distinguish between a range of different types of distraction, namely visual, cognitive and physical (manual) distraction; all of which have been shown to have disparate effects on driving performance "[46], [8], [47]”. Distraction remains largely unexplored in a public transport context. In addition to conventional driving [48], some research has focussed on distraction in the commercial transport sector, such as heavy goods vehicle [49], and truck driving 
“[50], [51]". In the context of bus driving, in particular, very little research has been undertaken, and the majority has focused on mobile phone use by bus drivers [52]. Although taxonomies of distraction sources have been developed for conventional driving [53], to date there has been no attempt to ascertain what sources of distraction exist within the context of bus driving. Further, the effects of distracted driving on bus driving performance remain unknown. Further research into the sources and effects of driver distraction in the public transport sectors is therefore required.

\subsection{Safety Driving Task}

Driving can be understood as fundamentally an information processing task: in order to achieve certain goals, the driver gathers information from the environment, interprets it, makes decisions, and carries out actions [54]. This process is not carried out once per journey but continually: there is continuous interaction between the driver and the environment (including the vehicle) as the driver monitors the results of previous actions and gathers new information as the vehicle moves through the road environment [55]. The process occurs on many levels; even the task of gaining information requires the driver to make decisions about what to attend to and when [56]. To successfully perform the driving task, the driver must be able to select necessary information and process it in time to make the appropriate decision and execute the required action. Allen, [57] and many authors subsequently [58], proposed that driving tasks can be categorised into three levels. The highest level is the strategic level, and includes decisions about where and when to drive, and which routes to take. These decisions can be made in advance of the journey, as well as during the journey. The second level is referred to as the tactical or manoeuvring level, and includes decisions such as whether to overtake a leading vehicle.

The lowest level is operational or vehicle control, and involves very short time-frame decisions such as whether to brake or accelerate to maintain vehicle speed. This lowest level is often modelled as a closed-loop servomechanism control system: the driver tries to minimise the difference between reference inputs (e.g. the appropriate position within the lane) and the output or results of their actions [59]. An alternative way to look at decision-making in driving uses [60] three levels of performance. He defines skill-based behaviour as automated patterns of behaviour occurring without conscious control; rule-based behaviour as the (not necessarily explicit) recognition of a situation and application of a stored rule; and knowledge-based behaviour as the testing of plans to achieve a goal against a mental model of the system. Each type of behaviour will result in different types of errors. [61] Noted that when these three types of behaviour are crossed with the three levels of driving tasks, there are nine possible states for a driver controlling a vehicle. However, for experienced drivers in normal situations, strategic decisions will be knowledge-based, tactical decisions will be rule-based, and control decisions will be skill-based.

This alternate way of looking at the pathway from input to response emphasises that different task performance levels require different levels of cognitive processing, which (as will become clear later) has implications for the likely level of disturbance from visual clutter. The results of actions at each of the three task levels can affect decisions at the other levels. For example, if a drivers' normal route is blocked or the signage obscured, the driver will not be able to turn (a tactical manoeuvre) at the planned location (and therefore will have to change their strategic level route plan). Drivers who decide to overtake a leading vehicle will have to perform the appropriate control actions in order to get into the correct position. Drivers who have difficulty braking on wet roads may make a strategic decision not to drive when it is raining. Thus while visual distraction may primarily affect one level of driving tasks, there may be flow-on effects to the other levels. 


\subsection{Cognitive and Visual Capacity in Driving}

Some sort of process, be that the development of automatic responses or better mental models of the road environment, reduces the mental workload of experienced drivers compared with novice drivers while the physical workload remains the same. Mental workload is the amount of mental effort required to complete a task; it also includes components of time pressure and perceived psychological stress [62]. It is a function of the demands of the task and the capacity of the person carrying out the task [63]. Mental workload can be measured in several ways: via physiological measures such as pupil dilation, heart rate variability, EEG signals; via secondary task performance, which is assumed to worsen as the primary task workload increases; or by asking the person under load, i.e. subjective ratings [64].

Mental workload will not always correspond to primary task performance, as explained below. Early researchers developed the Yerkes-Dodson law: plotting performance against arousal on a graph gives an inverted-U shape, with optimum performance at medium levels of arousal [65]. 'Arousal' in this context refers to how stimulated the person is, for example by noise, anxiety, or information.

This law can be adapted to describe the relationship between task demands, workload and performance. When task demands are below the optimum, drivers can improve performance only by exerting state-related effort that is, concentrating hard to prevent boredom [66], or increasing task difficulty to the optimum level [67]. When task demands are above the optimum, the driver will have to exert more task-related effort to maintain performance. In this area of the curve, performance may not show any effect of increased demand, but workload measures will. At a certain level of demand, the driver will be unable to maintain performance even with maximum effort, and the driving tasks will not be performed optimally [66]. To avoid overload, drivers may seek to limit the number of information sources they use when making decisions [68], but this strategy can also result in impaired driving if drivers make the wrong decision [69].

Consistent with the Yerkes-Dodson law, research has found that increasing the task demands in relatively complex situational environments will result in impaired driving performance. [70] Found that drivers missed more lights in a peripheral detection task while driving through busier and more complex environments. [71] Found negative effects on both reaction time and hit rate for a peripheral detection task when driving task difficulty was increased by external causes such as narrow curves or the appearance of an unexpected obstacle. [72] Found similar effects on secondary task performance when they increased workload by increasing the traffic density. [73] Found that drivers took longer to brake for critical events when they were given the task of counting the number of a certain type of pedestrian.

[74] notes that high workload can decrease the probability of drivers recognising hazards (and thus accurately perceiving the level of risk in a driving situation), as well as increase the probability of drivers making risky decisions due to time pressure. It should be noted that workload is not synonymous with performance decrements. When task-demand is low enough that drivers can compensate by increasing effort, adding further tasks may increase subjective workload without affecting performance [75]. However, even when it seems unlikely that an individual event or object causes driver stress or overload, the cumulative effect of sustaining attention through many such strain-inducing events source of stress which can reduce intentional capacity [76].

Although it may not be possible to declare an exact percentage, it is clear that the primary source of information when driving is visual [77].Drivers use vision to maintain situation awareness, respond to any hazards, and search for information to support decision-making. [78] Provides a taxonomy of visual driving tasks, comprising determination of position, speed, acceleration, heading angle and changes in heading angle; perception of obstacles, route indications, road users 
and traffic situations; and control over the selective visual perceptual system (i.e. movements of body, head and eyes to gather visual information). Tasks in the first set involve continuous monitoring of visual cues such as looming, and can be performed using peripheral vision "[79], [80]". These visual tasks, which form the basis for the lowest level of driving tasks (vehicle control), are less likely to be affected by visual clutter. (It is possible that high background complexity could affect optic flow rates and thus speed estimation, but as most Australian cars possess a working speedometer this is not considered as a major issue.)

The second set of visual tasks (perception of obstacles, route indications, road users and traffic situations) are most likely to be affected by visual clutter, which will in turn affect response tasks at the tactical/maneuvering level of driving. Although we perceive the world as if we have fully processed every visual stimulus within our field of view, the visual system is limited in the amount of information it can deliver to conscious awareness. As well as the cognitive limitation on the number of items that can be held in short-term memory [81], there is the visual limitation that less than one degree of the visual field can be processed by the highest resolution area of the retina [82]. While the brain can attend to areas other than where the eyes are focused, doing so impairs processing of the item at fixation [83]. This means that to read a sign, for example, the eyes must move over the text and the reader must attend to the text rather than other stimuli within the visual field. “[84], [85]" divides control of intentional selection into two modes: endogenous, in which selection is controlled by the goals of the observer, and exogenous, in which selection is controlled by the properties of the stimulus. He concludes that endogenous control can set the size and location of the intentional window (from the size of a single item to the size of the entire visual field), but that within the window, attention will automatically be allocated to the item with the largest local difference from its surroundings.

\section{Materials and Methods}

\subsection{Participants}

Standard abbreviations Sample drivers was selected from Setif 2 University, Total number of samples involved in this study was 300; (100 Females and 200 Males), the aged 20-35 years (mean $=25.9, \mathrm{SD}=5.6$ ) took part in the study. The driving experience between $02-10$ years (mean $=5$ years, $\mathrm{SD}=5.6$ ).

\subsection{Procedure}

Participants were tested individually in a single session of approximately $1-2 \mathrm{~h}$, including breaks to minimise fatigue. They completed the range of cognitive and vision tests, followed by the Useful Field of View test, the Hazard Perception Test, and the Hazard Change Detection Task. Prior to the testing session participants completed questionnaire detailing demographic information and driving behavior in a questionnaire adapted from previous studies “[86], [87]”.

\subsection{Measures}

\subsubsection{Cognitive Measures}

The cognitive test battery was designed to measure visuo-cognitive processing abilities that may theoretically be linked with Driving abilities and/or accident risk [14]. Visual processing speed was included as this is related to several of the other abilities important for driving (e.g. executive function, working memory) and has been shown to have independent associations with driving 
outcome measures. Components of executive function that were considered important to driving [88] included task switching and strategic working memory, although it is acknowledged that the general construct of executive function is difficult to define and in factor analytic studies is difficult to distinguish from fluid and working memory abilities [89]. Measures of visual closure were included because it was hypothesised that the ability to extract visual images from backgrounds would be important for hazard perception and hazard change detection. Visual closure has also been shown to be strongly related to driving performance "[90], [91]". Measures of visual working memory were included because the capacity to retain visual information in memory while processing is required during the driving task.

\subsubsection{Mini Mental State Examination (MMSE)}

The Mini Mental State Examination (MMSE) is a short, simple test of global cognitive function used to estimate the extent of any cognitive impairment [92]. It was administered according to standardised instructions and scoring proposed by Molloy and [93]. Participants answer questions assessing short-term memory, orientation in space and time, con-structional ability, executive functioning, and ability to follow instructions. Participants answer verbally, in writing, and by per-forming actions when requested. The MMSE is scored out of 30 and state of cognitive impairment can be interpreted as follows: 26-30, 'could be normal'; 20-25, 'mild'; 10-19, 'moderate'; 0-9, 'severe'[94].

\subsubsection{Spatial Ability (SA)}

Spatial ability was measured by tests of mental rotation and transformation using the card rotation test and the paper folding test, both adapted from [95]. In the Card Rotation test participants had to decide whether each of the eight rotated sample figures were flipped or non-flipped versions of the target figure. Participants were asked to complete as many items as possible in $3 \mathrm{~min}$. In the Paper Folding task, participants were shown a schematic of a square piece of paper being folded and then punched through, with stages depicting between one and three horizontal, vertical or diagonal folds. Participants had to select which of five alternatives depicted the pattern of holes that would be present in the unfolded square of paper. They were instructed to complete as many as possible of 10 items within $3 \mathrm{~min}$.

\subsubsection{Visual Measures}

Static visual acuity was tested with participants wearing their standard distance prescription, using a high and low contrast Bailey-Lovie (log MAR) chart at a working distance of $2.4 \mathrm{~m}$ under the recommended illumination conditions [96]. Visual acuity under both high and low contrast condition was scored on a letter by letter basis, where each letter correctly identified represented a score of 0.02 log units. Letter contrast sensitivity was determined using Pelli-Robson charts under the recommended testing conditions [97]. Participants were instructed to look at a line of letters and to guess the letter when they were not sure. Each letter was scored as 0.05 log units.

\subsubsection{Visual Acuity (VA)}

Visual acuity was assessed using the Freiburg Visual Acuity Test [98]. Participants indicated the orientation of a 'Tumbling E' optotype. Participants sat $1.65 \mathrm{~m}$ from a computer screen and responded using the arrows on the computer keyboard. The size of the optotype presented varied on each trial depending on the current estimated threshold of the participant, calculated via the best 
Parameter Estimate by Sequential Testing procedure [98]. There were 30 trials, with every sixth trial being an 'easy 'trial where the optotype size was significantly larger than the cur-rent estimated threshold. Acuity was recorded as the logarithm of the Minimum Angle of Resolution (log MAR), with lower scores representing better visual acuity.

\subsubsection{Colour Choise Reaction Time (CCRT)}

Computerised inhibition choice reaction task previously shown to discriminate safe from unsafe drivers [86]. Targets (red or blue cars) were presented in one of four quadrants of a grid on screen. Participants were instructed to respond to red targets appearing in the top right cell by pressing a right hand button, red targets in the top left required a response using a left hand button, and those in the bottom right and left cells required a foot response using right and left pedals respectively. Blue cars occurred on $11.1 \%$ of trials, and required a response inhibition (i.e. not pressing any buttons). The computer recorded reaction times and accuracy for each of 60 trials.

\subsubsection{Working Memory (WM)}

Digit span backwards was adapted from the Wechsler Adult Intelligence Scale-III [99]. A score was calculated as the sum of all correct responses. A Visual Working Memory task (Spatial Memory) constructed for this study involved the presentation of targets at different positions in a six-cell or a nine-cell grid at a rate of one per second. The grid was then replaced on screen by a distractor task involving a short sentence that participants were required to read aloud. Participants were then asked to press the appropriate cells in an empty grid in the same order as the targets had appeared. Presentation sequences ranged from two to nine targets, with two trials for each sequence. The test was scored as the number of correct responses. Finally, a computerized Lettersets task adapted from [100] involved the presentation of pairs of letter strings, ranging in length from two to ten letters.

\subsubsection{Measures of Capacity to Drive Safety (MCDR)}

\subsubsection{Useful Field of View (UFOV)}

UFOV is a computer-based test of visual attention and processing speed involving detection and localisation of briefly presented targets throughout the visual field [101]. There are three subtests: processing speed, divided attention, and selective attention. Four practice trials were first completed for all subtests. Two stimuli are used; a silhouette of a car and a truck, sized $2 \mathrm{~cm} \times 1.5 \mathrm{~cm}$. In the processing speed subtest, one of these stimuliis briefly presented within a central fixation box of 3 $\mathrm{cm} \times 3 \mathrm{~cm}$ at varying exposure durations across trials in central vision, and the observer indicates which stimulus they saw by clicking the appropriate symbol on the screen. For divided attention, one of the two stimuli appears briefly in central vision as before, and the car appears simultaneously in the periphery at one of the eight cardinals or intercardinal points, $12.5 \mathrm{~cm}$ from the centre of the display. Participants indicate which object was presented in central vision, and the location of the car in the periphery. The task for selective attention subtest is the same but with the addition of 47 distracters (triangles of the same size and luminance as the target stimuli) distributed evenly throughout the visual field. For each subtest, the score is exposure time (ms) for which $75 \%$ of responses is correct. UFOV total score was calculated by summing the score from each subtest. Test-retest reliability for total UFOV score is .88 [102]. 


\subsubsection{Hazard Perception Test (HPT)}

This test required participants to anticipate potential traffic conflicts in video clips of traffic scenes filmed from the driver's point-of-view [103] by pressing the relevant area of the touch screen whenever they identified a potential incident. Twenty-two traffic conflicts (across 20 traffic clips of between 15 and $40 \mathrm{~s}$ duration) were selected on the basis that (1) there were anticipatory cues available, and (2) the conflict became unambiguous such that nearly all participants would be expected to respond eventually. The software recorded a response time for each potential conflict (starting from the first moment that the potential conflict was detectable) and these were averaged to obtain an overall hazard perception response latency. Performance on this test has been validated against self-reported crashes using the sample on which the current study is based [104].

\subsubsection{Hazard Change Detection Task (HCDT)}

The Hazard Change Detection Task [105] was used to measure participants' ability to detect the presence of hazards independent of other factors (e.g. speed). The task used pairs of still images of traffic scenes,

which were displayed on a computer screen using the flicker paradigm [103]. Each pair of scenes (59 trials in total) contained an original and an altered image which were displayed for $250 \mathrm{~ms}$, and this was alternated with a gray mask (which was displayed for $80 \mathrm{~ms}$ ). Participants were asked to identify the difference between the two pictures by pressing on the screen as soon as they noticed the difference and the outcome measure was the mean reaction time for correct trials.

\subsection{Analysis}

Linear regression models were used to assess amount of variance in UFOV performance that could be accounted for by the predictor variables. Each subtest. and the total score were considered separately. Models were selected via backward elimination from an initial full model including Driving experience, Mini Mental State Examination (MMSE), Spatial ability, Visual acuity, Colour Choice Reaction Time (CRTC), Working memory, Useful Field of View (UFOV), Hazard Perception Test (HPT), Hazard Change Detection Task (HCDT).

Hierarchical multiple regression was used to address each of the main research questions. First, the relative importance of the cognitive and visual factors for predicting performance on the driving screening measures were evaluated in a regression model by entering all the cognitive factors and vision after adjusting for drive Safety. Interactions between driving experience and the cognitive and visual factors and between driving experience and the cognitive and visual factors were also tested to determine whether the effects of the factors were moderated by driving experience or sex. Understanding the role of driving experience in predicting the Capacity. 


\section{Results}

Table1. Descriptive statistics and intercorrelations among variables.

\begin{tabular}{|c|c|c|c|c|c|c|c|c|c|c|c|}
\hline Variable & $M$ & $S D$ & 1 & 2 & 3 & 4 & 5 & 6 & 7 & 8 & 9 \\
\hline Age (years) & 25.9 & 5.6 & & & & & & & & & \\
\hline Gender & $\mathrm{n} / \mathrm{a}$ & $\mathrm{n} / \mathrm{a}$ & & & & & & & & & \\
\hline $\begin{array}{l}\text { Driving } \\
\text { experience }\end{array}$ & 5 & 5,6 & & & & & & & & & \\
\hline MMSE & 31.62 & 12.09 & $\begin{array}{l}-.27 * \\
*\end{array}$ & $\begin{array}{l}.25^{*} \\
*\end{array}$ & $\begin{array}{l}-.32 * \\
*\end{array}$ & & & & & & \\
\hline $\begin{array}{l}\text { Visual } \\
\text { Acuity }\end{array}$ & 3.47 & 1.88 & $\begin{array}{l}-.24 * \\
*\end{array}$ & .08 & $.16^{*}$ & $-.36 * *$ & & & & & \\
\hline CRTC & 6.91 & 2.26 & $\begin{array}{l}-.30 * \\
*\end{array}$ & -.07 & .11 & $.31 *$ & $.50 * *$ & & & & \\
\hline $\begin{array}{l}\text { Working } \\
\text { Memory }\end{array}$ & 6.05 & 1.90 & $\begin{array}{l}-.21 * \\
*\end{array}$ & .07 & $.19 * *$ & $.26 * *$ & $.21^{* *}$ & $\begin{array}{l}-.30^{*} \\
*\end{array}$ & & & \\
\hline UFOV & $\begin{array}{l}131.6 \\
7\end{array}$ & $\begin{array}{l}101.9 \\
4\end{array}$ & $.50 * *$ & -.04 & $-.12 *$ & $\begin{array}{l}-.38^{*} \\
*\end{array}$ & $\begin{array}{l}-.23 * \\
*\end{array}$ & $\begin{array}{l}-.18^{*} \\
*\end{array}$ & $.51 * *$ & & \\
\hline HPT & 5.55 & 0.96 & $.39 * *$ & -.09 & $\begin{array}{l}-.22 * \\
*\end{array}$ & $-.32 *$ & $\begin{array}{l}-.36^{*} \\
*\end{array}$ & $\begin{array}{l}-.17 * \\
*\end{array}$ & $.24 * *$ & $\begin{array}{l}-.23 * \\
*\end{array}$ & \\
\hline HCDT & 8.03 & 2.58 & $.49 * *$ & $\begin{array}{l}-.14 \\
*\end{array}$ & $\begin{array}{l}-.17 * \\
*\end{array}$ & $\begin{array}{l}-.41 * \\
*\end{array}$ & $\begin{array}{l}-.33 * \\
*\end{array}$ & $\begin{array}{l}-.29 * \\
*\end{array}$ & $\begin{array}{l}-.26 * \\
*\end{array}$ & $-.19^{*}$ & $\begin{array}{l}.45^{*} \\
*\end{array}$ \\
\hline
\end{tabular}

MMSE = Mini-Mental State Examination,

CRTC $=$ Colour Choice Reaction Time (CRTC),

UFOV = Useful Field of View test.

HPT $=$ Hazard Perception Test.

HCDT $=$ Hazard Change Detection Task.

$* \mathrm{p}<.05 . * * \mathrm{p}<.01$

All cognitive and visual measures showed moderate to strong associations with chronological driving experience and the driver screening instruments. The three driver screening measures also were individually correlated with the majority of the measures of cognitive and visual function.

\subsection{Exploratory Factor Analysis of Visual and Cognitive Measures}

Factor analysis of the cognitive and vision measures produced a factor solution was accepted. The matrix for the final model is shown in Table 2.

The first factor was defined by Mini-Mental State Examination (MMSE), number comparison, CRTC (both the RT and number correct measures), Visual acuity, and Useful Field of View test (UFOV), Hazard Perception Test (HPT), Hazard Change Detection Task (HCDT), suggesting these measures define a latent variable of fluid-executive abilities involving speed, visual attention and task-switching. It was therefore called 'Speed/Executive' (Speed/Exec). The factor to emerge was the visual acuity/visual contrast sensitivity factor Vision), followed by Visual Closure (Closure) which was defined by the three measures of closure as planned. The spatial measures plus a factor called 'Spatial'. Working memory factor was indicated by loadings of driving experience. 
Table 2. Matrix from factor analysis of cognitive and visual function tests $(\mathrm{N}=300)$.

\begin{tabular}{l|lllll}
\hline Matrix from factor & Speed/Execa $^{a}$ & Visionb $^{b}$ & Closure $^{c}$ & Spatial & Nkmem $^{d}$ \\
\hline Visual Search & 0.646 & -0.201 & 0.052 & 0.002 & -0.188 \\
Number Comparison & 0.646 & 0.050 & 0.192 & 0.180 & 0.155 \\
CRTC Accuracye & 0.444 & 0.074 & -0.044 & -0.044 & 0.049 \\
Snowy Pictures & 0.125 & 0.081 & 0.114 & -0.07 & -0.014 \\
MMSE & -0.765 & 0.028 & 0.047 & 0.048 & -0.160 \\
Visual acuity & 0.039 & 1.064 & 0.004 & -0.015 & 0.027 \\
CRTC Reaction Timee & -0.501 & 0.162 & 0.010 & 0.121 & 0.073 \\
Working Memory & 0.430 & -0.285 & 0.226 & -0.741 & \\
UFOV & -0.342 & 0.072 & -0.025 & 0.722 & -0.183 \\
HPT & -0.378 & 0.185 & 0.025 & 0.559 & -0.178 \\
HCDT & -0.785 & 0.078 & 0.007 & 0.078 & -0.160 \\
Spatial & -0.441 & 0.387 & -0.146 & & \\
\hline
\end{tabular}

a Speed/Exec = executive-speed.

b Vision = visual acuity.

c Closure $=$ visual closure.

$\mathrm{d} \mathrm{Wk}=$ working memory.

\subsection{Regression of Capacity to Drive Safety on Cognitive and Visuall Factors}

Table 3 shows the results of hierarchical multiple regressions of the cognitive and visual factors adjusting driving experience. Driving experience was significantly associated with performance on UFOV and HCDT, and gender was associated with HCDT (males faster than females). Speed/Exec and Spatial were associated with UFOV, HPT and HCDT. Vision was only associated with HPT. Closure was not associated with any of the outcome measures. Working memory was associated with UFOV only. Health was not correlated with UFOV, HPT or HCDT and inclusion of the SF36 score in the regression models did not change the findings (results not shown). Over $44 \%$ of variance in UFOV, $55 \%$ of variance in the HCDT and over $33 \%$ of variance in the HPT was explained by the cognitive and visual measures. The Driving experience by Vision interaction was non-significant in all models.

Driving experience and cognitive ability interactions were all non-significant except for the driving experience by Speed/Exec interaction which was significant for the HPT (beta 1.98, p $<.01$ ) and accounted for 3\% of the variance in HPT. Evaluation of the interaction showed that the association between HPT and Speed/Exec was non-significant in adults aged over 30. Sex by cognitive ability interactions and the sex by vision interaction were non-significant in all regression models. 
Table.3 Hierarchical multiple regression models evaluating shared variance among age, cognitive and vision factors.

\begin{tabular}{lccc}
\hline & $\mathrm{UFOV}^{\mathrm{a}}$ & $\mathrm{HPT}^{\mathrm{b}}$ & $\mathrm{HCDT}^{\mathrm{c}}$ \\
\hline & $\begin{array}{c}\mathrm{Incr}^{\mathrm{d}} \mathrm{R}^{2} \\
\mathrm{~N}=300\end{array}$ & $\begin{array}{c}\text { Incr. }^{\mathrm{d}} \\
\mathrm{N}=300\end{array}$ & $\begin{array}{l}\mathrm{Incr}^{\mathrm{d}} \mathrm{R}^{2} \\
\mathrm{~N}=300\end{array}$ \\
\hline Model 1 & & & $.078^{* *}$ \\
Driving experience & $.057^{* *}$ & $.015^{* *}$ & $.478^{* *}$ \\
Vision/Cognitive & $.557^{* *}$ & $.315^{* *}$ & \\
Model 2 & & & $.578^{* *}$ \\
Vision/Cognitive & $.457^{* *}$ & $.215^{* *}$ & $.078^{* *}$ \\
Driving experience & $.057^{* *}$ & $.015^{* *}$ & \\
Model 3 & & & $.058^{* *}$ \\
Driving experience & $.067^{* *}$ & $.035^{* *}$ & $.678^{* *}$ \\
Vision & $.357^{* *}$ & $.415^{* *}$ & $.578^{* *}$ \\
Cognitive & $.357^{* *}$ & $.615^{* *}$ & \\
\hline
\end{tabular}

a UFOV = Useful Field of View test.

b HPT = Hazard Perception Test.

c HCDT = Hazard Change Detection Task.

$\mathrm{d}$ incr. $=$ incremental.

$* \mathrm{p}<.05$.

$* * \mathrm{p}<.01$

\subsection{Evaluation of Driving Experience-related Variance in Screening Measures Explained by Vision and Cognitive Factors}

For the UFOV, driving experience explained 30\% of the variance and vision and cognition only explained an additional $20 \%$ of variance. When driving experience was entered after the visual and cognitive factors it explained about $8 \%$ of the variance, indicating that about $85 \%$ of age-related variance in the UFOV was explained by the cognitive and vision factors. Driving experience explained $26 \%$ of variance in the HPT, and about $98 \%$ of this was shared with the cognitive and vision factors. Age no longer made a statistically significant contribution to performance on the HPT after adjusting for the cognitive and visual factors. Driving experience $38 \%$ of variance in HCDT and $73 \%$ of this was shared with the cognitive and vision factors.

Table 3 shows hierarchical regressions that evaluate the extent to which the contribution of vision is shared with the cognitive factors. Vision explained about 5\% of variance in HPT after controlling for age and the cognitive factors, but made minimal unique contribution to UFOV and HCDT in the same models.

\section{Discussion}

The study investigates a Multifactorial Model for identifying driver distraction and visual abilities for safety driving behavior to specifically increase understanding of how cognitive and visual functions independently and jointly explain performance on validated measures of the Capacity to Drive Safety. As expected, a large proportion of variance in the outcome measures was explained by driving experience. The first research question we aimed to investigate was the relative importance of visual acuity and cognitive abilities, in relation to driving risk. The cognitive factors accounted for a far greater proportion of variance, although it should be noted that there 
were many more cognitive than visual measures included.

This finding may suggest that relying on visual acuity rather than cognitive screening is not the optimal approach to assessment and screening of drivers. Ideally, the most sensitive visual and cognitive function measures would be included in evaluations of driver safety. Although visual acuity is only one domain of visual function and there are other visual abilities with much stronger associations with driving performance, such as motion sensitivity it is the domain currently assessed in driver licensing in many jurisdictions [86].

The second research question we aimed to address was the relative importance of cognitive speed vs other cognitive abilities, in explaining performance on the measures of Capacity to Drive Safety. However in our factor analysis, a pure speed measure did not emerge, but rather, processing speed and executive type measures formed a single factor suggesting that these measures share common variance and are inextricably linked consistent with previous research "[106], [107]”. This factor was strongly associated with our outcome measures and did have the largest effect on UFOV and HCDT. We conclude therefore that processing speed and speeded executive tasks such as Trail Making are the strongest correlates of integral driving skills in later life [108]. However, this study also found that spatial ability was significantly associated with performance on all outcome measures, in a model that adjusted for Speed/Exec.

Working memory was also important for performance on UFOV and HCDT, as both tasks involve a memory load. As driving involves judgment of location, distance and speed and general spatial awareness, the consistent finding that spatial ability was associated with the Capacity to Drive Safety finding has strong ecological validity. Overall, these findings indicate that visual-cognitive abilities known to decline with age and which have a strong genetic component are those that also predict driving skills, and that a wide range of cognitive abilities are involved in safe driving [109].

The third research question we addressed was the extent to which driving experience-related variance in our measures of the Capacity to Drive Safety could be explained by visual and cognitive function. Consistent with previous research measures of Capacity to Drive Safety were negatively associated with chronological driving experience [110]. Similarly, all individual cognitive and visual measures showed negative bivariate correlations with driving experience.. However, investigation of the interaction between age and Speed/Exec showed that among the participants in the sample, the correlation between HPT response time and Speed/Exec was no longer significant.

Although most of the driving experience -related variance in performance on measures of safe driving capacity was shared with the cognitive measures, there were still independent effects of cognitive function on all the outcome measures. This shows that chronological driving experience alone is inadequate for predicting driver risk, and that cognitive screening will improve assessments based purely on driving experience. Future advances in driver screening and interventions require the development of more sophisticated models of how factors inter-relate to influence driving performance under different conditions.

This study had several limitations. Although the electoral roll was used as a sampling frame, the response rate was low and this is likely to have led to sample bias towards a high functioning group. Hence the results are likely to underestimate the true strength of associations among measures. Analysis of the group who did not complete all outcome measures showed they were driving experience; less educated and had poorer performance on the two cognitive factors with the strongest associations with the driving outcome measures. This suggests that a limitation of the screening measures used is that they may be too challenging or demanding for individuals who are at greatest risk of unsafe driving. Hence researchers need to develop measures that are acceptable to the widest possible range of driving experience who need to be screened. 


\section{Conclusion}

This study lacked an on-road driving test or driving simulator to validate the screening measures, and the HCDT has not been validated against an on-road test. There are many types of errors that driving experience make while driving and it is unclear at this stage whether the UFOV, HPT, and HDCT are indicative of similar or different types of on-road driving errors. [111] Further research is required to evaluate these outcome measures jointly against both crash data and on-road driving assessments. The study was also limited in the range of visual function measures included. Previous research has shown that visual measures of motion sensitivity (Wood et al., 2008) are strong predictors of on-road driving performance, however we chose to include only standardized measures of visual function, that are more likely to be administered in a driver licensing situation. [86].

The current study has several practical implications. Our results describe abilities that are strongly related to the Capacity to Drive Safety and demonstrate that on average these abilities decline with age. However this does not imply that driving experience can be used as an indicator of driving ability. At the individual level, assessment of actual visual and cognitive function is likely to be a fairer and more accurate indicator of driving ability than chronological age. There are large individual differences in abilities even at driving experience and individual assessment is required to determine a person's actual visual and cognitive abilities. Our results may also be used to guide the development of driving environments, which enable driving experience to drive safety despite changes in cognitive and visual function. Finally, understanding the key abilities involved in safe driving is essential for the development of training interventions to improve driver skill and maintain safe driving for as long as possible.

\section{References}

[1] Hosking, S.G., Young, K.L., Regan, M.A., 2009. The effects of text messaging on young drivers. Human Factors 51, $581 e 592$

[2] Regan, M.A., Lee, J.D., Young, K.L., 2008a. Driver Distraction: Theory, Effects and Mitigation. CRC Press, Boca Raton, Florida.

[3] Salmon, P.M., Stanton, N.A., Jenkins, D.P., Walker, G.H., 2010a. Hierarchical Task Analysis Versus Cognitive Work Analysis: Comparison of Theory, Methodology, and Contribution to System Design. Theoretical Issues in Ergonomics Science. Ifirst, 2nd February, pp. 1e28.

[4] Young, K.L., Lenné, M.G., 2010. Driver engagement in distracting activities and the strategies used to minimise risk. Safety Science 48, 326-332.

[5] Klauer, S.G., Dingus, T.A., Neale, V.L., Sudweeks, J.D., Ramsey, D.J., 2006. The Impact of Driver Inattention on Near-crash/crash risk: An Analysis Using the 100-Car Naturalistic Driving Study Data. Virginia Tech Transportation Institute, Blacksburg, Virginia.

[6] Rakauskas, M.E., Gugerty, L.J., Ward, N.J., 2004. Effects of naturalistic cell phone conversations on driving performance. Journal of Safety Research 35 (4), 453-464.

[7] Strayer, D.L., Drews, F.A., 2004. Profiles in driver distraction: effects of cell phone conversations on younger and older drivers. Human Factors 46, 640.

[8] Engström, J., Johansson, E., Ostlund, J., 2005. Effects of visual and cognitive load in real and simulated motorway driving. Transportation Research Part F 8, 97e120.

[9] Reed, M.P., Green, P.A., 1999. Comparison of driving performance on-road and in a low-cost simulator using a concurrent telephone dialling task. Ergonomics 42, 1015 e1037.

[10] Kass, S.J., Cole, K.S., Stanny, C.J., 2007. Effects of distraction and experience on situation awareness and simulated driving. Transportation Research Part F: Traffic Psychology and Behaviour 10, 321e329.

[11] Burns, P.C., Parkes, A., Burton, S., Smith, R.K., Burch, D., 2002. How Dangerous is Driving with a Mobile Phone? Benchmarking the Impairment to Alcohol. TRL Limited, Crowthorne, UK. 
[12] Lee, J.D., Caven, B., Haake, S., Brown, T.L., 2001. Speech-based interaction with invehicle computers: Tthe effect of speech-based e-mail on drivers' attention to the roadway. Human Factors 43, 631e 640.

[13] Nunes, L.M., Recarte, M.A., 2002. Cognitive demands of hands-free phone conversation while driving. Transportation Research Part F: Traffic Psychology and Behaviour 5, $133 e 144$.

[14] Anstey, K.J., Wood, J., Lord, S., Walker, J.G., 2005b. Cognitive, sensory and physical factors enabling driving safety in older adults. Clin. Psychol. Rev. 25 (1), 45-65.

[15] Horswill, M.S., Anstey, K.J., Hatherly, C., Wood, J.M., Pachana, N.A., 2011. Older drivers' insight into their hazard perception ability. Accid. Anal. Prev. 43, 2121-2127.

[16] Okonkwo, O.C., Crowe, M., Wadley, V.G., Ball, K., 2008. Visual attention and selfregulation of driving among older adults. Int. Psychogeriatr. 20 (1), 162-173.

[17] Cole, B.L., 2002. Who's responsible for safe vision on the roads? Clin. Exp. Optom. 85 (4), 207-209.

[18] Jobe, J.B., Smith, D.M., Ball, K.K., Tennestedt, S.L., Marsiske, M., Willis, S.L., Rebok, G.W., Morris.

[19] Roenker, D.L., Cissell, G.M., Ball, K.K., Wadley, V.G., Edwards, J.D., 2003. Speedof- processing and driving simulator training result in improved driving performance. Hum. Factors 45 (2), 218-233.

[20] Edwards, J.D., Ross, L.A., Wadley, V.G., Clay, O.J., Crowe, M., Roenker, D.L., Ball, K.K., 2006. The useful field of view test: normative data for older adults. Arch. Clin. Neuropsychol. 21 (4), 275-286.

[21] Horswill, M.S., Kemala, C.N., Wetton, M., Scialfa, C.T., Pachana, N.A., 2010b. Improving older drivers' hazard perception ability. Psychol. Aging 25 (2), 464-469.

[22] Ball, K.K., Owsley, C., 1993. The useful field of view test: a new technique for evaluat-ing age-related declines in visual function. Journal of the American OptometricAssociation 64 (1), 71-79.

[23] Clay, O.J., Wadley, V.G., Edwards, J.D., Roth, D.L., Roenker, D.L., Ball, K.K.,2005. Cumulative meta-analysis of the relationship between usefulfield of view and driving performance in older adults: current andfuture implications. Optometry and Vision Science 82 (8), 724-731.

[24] Mathias, J.L., Lucas, L.K., 2009. Cognitive predictors of unsafe driving in olderdrivers: a meta-analysis. International Psychogeriatrics 21 (4), 637-653.

[25] Gentzler, M.D., Smither, J.A., 2012. A literature review of major perceptual, cognitive,and/or physical test batteries for older drivers. Work 41 (Suppl.1), 5381-5383.

[26] Ball, K.K., Owsley, C., 1993. The useful field of view test: a new technique for evaluat-ing age-related declines in visual function. Journal of the American OptometricAssociation 64 (1), 71-79.

[27] Clay, O. J., Wadley, V., Edwards, J. D., Roth, D., Roenker, D. L., \& Ball, K. K. (2005). Cumulative meta-analysis of the relationship between useful field of view and driving performance in older adults: Current and future implications. Optometry and Vision Science, 82, 724-731.

[28] Gentzler, M.D., Smither, J.A., 2012. A literature review of major perceptual, cognitive, and/or physical test batteries for older drivers. Work 41 (Suppl.1), 5381-5383,http://dx.doi.org/10.3233/wor-2012-0825-5381.

[29] Edwards, J.D., Vance, D.E., Wadley, V.G., Cissell, G.M., Roenker, D.L., Ball, K.K., 2005.Reliability and validity of useful field of view test scores as administered bypersonal computer. Journal of Clinical and Experimental Neuropsychology 27(5), 529-543.

[30] Ball, K.K., Roenker, D.L., Bruni, J.R., 1990. Developmental changesin attention and visual search throughout adulthood. In: Enns,J.T. (Ed.), Advances in Psychology. North-Holland, pp. 489-508.

[31] Ball, K.K., 1997. Attentional problems and older drivers. AlzheimerDisease and Associated Disorders 11 (Suppl. 1), 42-47.

[32] Carrasco, M., 2011. Visual attention: the past 25 years. Vision Research 51 (13),1484-1525.

[33] Lunsman, M., Edwards, J.D., Andel, R., Small, B.J., Ball, K.K., Roenker, D.L., 2008. Whatpredicts changes in useful field of view test performance? Psychology and Aging23 (4), 917-927.

[34] Hoffman, L., Yang, X., Bovaird, J.A., Embretson, S.E., 2006. Measuring atten-tional ability in older adults: development and psychometric evaluation ofDriverscan. Educational and Psychological Measurement 66 (6), 984-1000.

[35] Rensink, R.A., O'Regan, J.K., Clark, J.J., 1997. To see or not to see: the need forattention to perceive changes in scenes. Psychological Science 8 (5), 368-373.

[36] Rensink, R.A., 2002. Change detection. Annual Review of Psychology 53, 245-277.

[37] Anstey, K.J., Wood, J., 2011. Chronological age and age-related cognitive deficits are associated with an increase in multiple types of driving errors in late-life. Neuropsychology, PMID: 21574713. 
[38] Horswill, M.S., Marrington, S.A., Mccullough, C.M., Wood, J., Pachana, N.A., Mcwilliam, J., Raikos, M.K., 2008. The hazard perception ability of older drivers. J. Gerontol.: Psychol. Sci. 63B (4), 212-218.

[39] Mckenna, F.P., Horswill, M.S., 1999. Hazard perception and its relevance for driver licensing. J. Int. Assoc. Traffic Saf. Sci. 23, 26-41.

[40] McKenna, F.P., Crick, J.L., 1991. Hazard Perception in Drivers: A Methodology for Testing and Training (Final Report). Transport and Road Research Laboratory, Crowthorne, England.

[41] Simons, D.J., Rensink, R.A., 2005. Change blindness: past, present, and future. Trends Cogn. Sci. 9 (1), 16-20.

[42] Rensink, R.A., 2002. Change detection. Annu. Rev. Psychol. 53, 245-277.

[43] Caird, J.K., Edwards, C.J., Creaser, J.I., Horrey, W.J., 2005. Older driver failures of attention at intersections: using change blindness methods to assess turn decision accuracy. Hum. Factors 47 (2), 235-249.

[44] Pringle, H.L., Irwin, D.E., Kramer, A.F., Atchley, P., 2001. The role of attentional breadth in perceptual change detection. Psychon. Bull. Rev. 8 (1), 89-95.

[45] Wetton, M.A., Horswill, M.S., Hatherly, C., Wood, J.M., Pachana, N.A., Anstey, K.J., 2010. The development and validation of two complementary measures of drivers' hazard perception ability. Accid. Anal. Prev. 42 (4), 1232-1239.

[46] Consiglio, W., Driscoll, P., Witte, M., Berg, W.P., 2003. Effect of cellular telephone conversations and other potential interference on reaction time in a braking response. Accident Analysis and Prevention 35 (4), $495 e 500$.

[47] Amditis, A., Pagle, K., Joshi, S., Bekiaris, E., 2010. Driver-vehicle-environment monitoring for on-board driver support systems: lessons learned from design and implementation. Applied Ergonomics 41 (2), 225-235.

[48] Lansdown, T.C., Burns, P.C., Parkes, A.M., 2004. Perspectives on occlusion and requirements for validation. Applied Ergonomics 35 (3), 225-232.

[49] Noy, Y.I., Lemoine, T.L., Klachan, C., Burns, P.C., 2004. Task interruptability and duration as measures of visual distraction. Applied Ergonomics 35 (3), $207 e 213$.

[50] Hanowski, R.J., Perez, M.A., Dingus, T.A., 2005. Driver distraction in long-haul truck drivers. Transportation Research Part F: Traffic Psychology and Behaviour 8 (6), 441e458.

[51] Olson, R.L., Hanowski, R.J., Hickman, J.S., Bocanegra, J., 2009. Driver Distraction in Commercial Vehicle Operations. Report no. FMCSA-RRR-09-242. Federal Motor Carrier Safety Administration, Washington, DC.

[52] Chen, W.-H., Lin, T.-W., Su, J.-M., Lee, S.-W., Hwang, S.-L., Hsu, C.-C., Lin, C.-Y., 2006. The effect of using in-vehicle communication system on bus drivers' performance in car-following tasks. In: 13th World Congress on Intelligent Transport Systems, London, UK.

[53] Stutts, J., Feaganes, J., Reinfurt, D., Rodgman, E., Hamlett, C., Gish, K., Staplin, L., 2005. Drivers' exposure to distractions in their natural driving environment. Accident Analysis and Prevention 37, $1093 e 1101$.

[54] Senders, J., Kristofferson, A., Levison, W., Dietrich, C., \& Ward, J. (1967). The Attentional Demand of Automobile Driving. Highway Research Record, 195, 15-32.

[55] Sheridan, T. B. (2004). Driver distraction from a control theory perspective. Human Factors, 46(4), 587-599.

[56] Wickens, C. D. (1987). Attention. In P. A. Hancock (Ed.), Human Factors Psychology (pp. 29-70). Amsterdam: Elsevier Science.

[57] Allen, T. M., Lunenfeld, H., \& Alexander, G. J. (1971). Driver information needs. Highway Research Record, 366, 102-114. van der Molen, H. H., \& Botticher, A. M. T. (1988). A hierarchical risk model for traffic participants. Ergonomics, 31(4), 537-555.

[58] van der Molen, H. H., \& Botticher, A. M. T. (1988). A hierarchical risk model for traffic participants. Ergonomics, 31(4), 537-555.

[59] Flach, J. M. (1999). Beyond error: the language of coordination and stability. In P. A. Hancock (Ed.), Human Performance and Ergonomics (pp. 109-128). San Diego: Academic Press.

[60] Rasmussen, J. (1987). Cognitive control and human error mechanisms In J. Rasmussen, K. Duncan \& J. Leplat (Eds.), New Technology and Human Error (pp. 53-61). Chicester, UK: John Wiley \& Sons.

[61] Ranney, T. A. (1994). Models of driving behavior: A review of their evolution. Accident Analysis \& Prevention, 26(6), 733-750.

[62] Reid, G. B., \& Nygren, T. E. (1988). The subjective workload assessment technique: a scaling procedure for measuring mental workload. In P. A. Hancock \& N. Meshkati (Eds.), Human Mental Workload (pp. 185-218). North-Holland: Elsevier Science Publishers.

[63] de Waard, D. (2002). Mental Workload. In R. Fuller \& J. Santos (Eds.), Human factors for highway engineers. 
[64] Kantowitz, B. H. (1987). Mental Workload. In P. A. Hancock (Ed.), Human Factors Psychology.

[65] Wickens, C. D. (1993). Engineering Psychology and Human Performance (2 ed.). New York: HarperCollins.

[66] de Waard, D., \& Brookhuis, K. (1997). On the measurement of driver workload. In T. Rothengatter \& E. Carbonell Vaya (Eds.), Traffic and Transport Psychology (1 ed., pp. 161-171).

[67] Wright, P. (1974). The harassed decision maker: time pressures, distractions, and the use of evidence. Journal of Applied Psychology, 59(5), 555-561.

[68] Cooper, P. J., \& Zheng, Y. (2002). Turning gap acceptance decision-making: the impact of driver distraction. Journal of Safety Research, 33, 321-335.

[69] Lee, P. N. J., \& Triggs, T. J. (1976). The effects of driving demand and roadway environment on peripheral visual detections. ARRB Proceedings, 8(Session 25), 7-12.

[70] Martens, M. H., \& van Winsum, W. (2000). Measuring distraction: the Peripheral Detection Task. From http://www-nrd.nhtsa.dot.gov/departments/nrd-13/driver-distraction/Welcome.htm.

[71] Baldwin, C. L., and J. T. Coyne. 2003. "Mental Workload as a Function of Traffic Density: Comparison of Physiological, Behavioral, and Subjective Indices." In Proceedings of the 2nd International Driving Symposium on Human Factors in Driver Assessment, Training and Vehicle Design, edited by D.V.

[72] Wood, C., Gray, R., Young, J., Summers, J., Torkkola, K., \& Massey, N. (2003). Inattentional blindness while driving. Paper presented at the Driving Assessment 2003: Second International Driving Symposium on Human Factors in Driver Assessment, Training, and Vehicle Design. From http://ppc.uiowa.edu/Driving-Assessment/http://ppc.uiowa.edu/drivingassessment/2003/Summaries/Downloads/do wnload.html.

[73] Hoyos, C. G. (1988). Mental load and risk in traffic behaviour. Ergonomics, 31(4), 571-584.

[74] Slick, R. F., Cady, E. T., \& Tran, T. Q. (2005). Workload changes in teenaged drivers driving with distractions. Paper presented at the Driving Assessment 2005: Third International Driving Symposium on Human Factors in Driver Assessment, Training and Vehicle Design. From http://ppc.uiowa.edu/Driving-Assessment/.

[75] Hancock, P. A., \& Warm, J. (1989). A dynamic model of stress and sustained attention. Human Factors, 31(5), 519-537.

[76] Sivak, M. (1996). The information that drivers use: is it indeed 90\% visual? Perception, 25, 1081-1089.

[77] Wierda, M. (1996). Beyond the eye: cognitive factors in drivers' visual perception. In A. G. Gale, I. D. Brown, C. M. Haslegrave \& S. P. Taylor (Eds.), Vision in Vehicles - V (pp. 97-105). Amsterdam: Elsevier.

[78] Summala, H., Lamble, D., \& Laakso, M. (1998). Driving experience and perception of the lead car's braking when looking at in-car targets. Accident Analysis \& Prevention, 30(4), 401-407.

[79] Summala, H., Nieminen, T., \& Punto, M. (1996). Maintaining lane position with peripheral vision during in-vehicle tasks. Human Factors, 38(3), 442-451.

[80] Broadbent, D. E. (1958). Immediate memory and the shifting of attention. In Perception and communication (pp. 210-243). Elmsford, NY, US.: Pergamon Press.

[81] Findlay, J. M., \& Gilchrist, I. D. (2003). Active Vision: The Psychology of Looking and Seeing. New York: Oxford University Press.

[82] Posner, M. I. (1980). Orienting of attention. Quarterly Journal of Experimental Psychology, 32, 3-25.

[83] Theeuwes, J. (1993). Visual selective attention: A theoretical analysis. Acta Psychologica, 83, 93-154.

[84] Theeuwes, J. (1994). Endogenous and exogenous control of visual selection. Perception, 23, 429-440.

[85] Wood, J.M., Anstey, K.J., Kerr, G.K., Lacherez, P.F., Lord, S., 2008. A multidomain approach for predicting older driver safety under in-traffic road conditions. J. Am. Geriatr. Soc. 56 (6), 986-993.

[86] Anstey, K.J., Wood, J., Kerr, G., Caldwell, H., Lord, S.R., 2009. Different cognitive profiles for single compared with recurrent fallers without dementia. Neuropsychology 23 (4), 500-508.

[87] Miyake, A., Friedman, N.P., Emerson, M.J., Witzki, A.H., Howerter, A., Wager, T.D., 2000. The unity and diversity of executive functions and their contributions to complex "Frontal lobe" Tasks: a latent variable analysis. Cogn. Psychol. 41 (1), 49-100.

[88] Salthouse, T.A., 2005. Relations between cognitive abilities and measures of executive functioning. Neuropsychology 19 (4), 532-545.

[89] Staplin, L., Lococo, K., Gish, K.W., Decina, L., 2003b. Model Driver Screening and Evaluation Program Final Technical Report, vol. 2: Maryland Pilot Older Driver Study. National Highway Transport Safety Administration, Washington, DC. 
[90] Ball, K.K., Roenker, D.L., Wadley, V.G., Edwards, J.D., Roth, D.L., Mcgwin Jr., G., Raleigh, R., Joyce, J.J., Cissell, G.M., Dube, T., 2006. Can high-risk older drivers be identified through performance-based measures in a department of motor vehicles setting? J. Am. Geriatr. Soc. 54 (1), 77-84.

[91] Folstein, M.F., Folstein, S.E., McHugh, P.R., 1975. 'Mini mental state'.A practical method for grading the cognitive state of patientsfor the clinician. Journal of Psychiatric Research 12 (3), 189-198.

[92] Molloy, D.W., Standish, T.I.M., 1997. A guide to the standardized Mini-Mental State Examination. International Psychogeriatrics 9 (Suppl. 1), 87-94.

[93] Vertesi, A., Lever, J.A., Molloy, D.W., Sanderson, B., Tuttle, I., Pokoradi, L., Principi,E., 2001. Standardized mini-mental state examination: use and interpretation.Canadian Family Physician 47 (October) 2018-2023.

[94] French, J.W., Ekstrom, R.B., Price, L.A., 1963. Manual for Kit of Reference Tests for Cognitive Factors. Educational Testing Service, Princeton, New Jersey.

[95] Bailey, I.L., Lovie, J.E., 1976. New design principles for visual acuity letter charts. Am. J. Optom. Physiol. Opt. 53, 740-745.

[96] Pelli, D.G., Robson, J.G., Wilkins, A.J., 1988. The design of a new letter chart measuring contrast sensitivity. Clin. Vis. Sci. 2, 187-199.

[97] Bach, M., 1996. The Freiburg visual acuity test - automatic measure-ment of visual acuity. Optometry and Vision Science 73 (1), 49-53.

[98] Wechsler, D., 1997. Wechsler Adult Intelligence Scale, 3rd ed. The Psychological Corporation, San Antonio, TX.

[99] Anstey, K.J., Smith, G.A., 1999. Interrelationships among biological markers of aging, health, activity, acculturation, and cognitive performance in late adulthood. Psychol. Aging 14 (4), 605-618.

[100] Wetton, M.A., Horswill, M.S., Hatherly, C., Wood, J.M., Pachana, N.A., Anstey, K.J., 2009. The development and validation of two complementary measures of older drivers' hazard perception ability. In: Experimental Psychology Conference, Wollongong, NSW, Australia.

[101] Horswill, M.S., Anstey, K.J., Hatherly, C.G., Wood, J.M., 2010a. The crash involvement of older drivers is associated with their hazard perception latencies. J. Int. Neuropsychol. Soc., 1-6.

[102] Marrington, S.A., Horswill, M.S., Wood, J.M., 2008. The effect of simulated cataracts on drivers' hazard perception ability. Optom. Vis. Sci. 85 (12), 1121-1127.

[103] Daigneault, G., Joly, P., Frigon, J.Y., 2002. Executive functions in the evaluation of accident risk of older drivers. J. Clin. Exp. Neuropsychol. 24 (2), 221-238.

[104] Decker, S.L., Hill, S.K., Dean, R.S., 2007. Evidence of construct similarity in executive functions and fluid reasoning abilities. Int. J. Neurosci. 117 (6), 735-748.

[105] Finkel, D., Pedersen, N.L., Pedersen, 2004. Processing speed and longitudinal trajectories of change for cognitive abilities: the Swedish adoption/twin study of aging. Aging Neuropsychol. Cogn. 11, 325-345.

[106] Wood, J.M., Anstey, K.J., Lacherez, P.F., Kerr, G.K., Mallon, K., Lord, S.R., 2009a. The onroad difficulties of older drivers and their relationship with self-reported motor vehicle crashes. J. Am. Geriatr. Soc. 57 (11), 2062-2069.

[107] Wolfe, J.M., Horowitz, T.S., 2004. What attributes guide the deployment of visualattention and how do they do it? Nature Reviews Neuroscience 5 (6), 495-501,1038/nrn1411.

[108] Barr, L.C., Yang, D.C.Y., Ranney, T.A., 2003. Exploratory analysis of truck driver distraction using naturalistic driving data. In: Proceedings of the 82nd Annual Meeting of the Transportation Research Board, Washington, DC, 2003.

[109] Cosman, J.D., Lees, M.N., Lee, J.D., Rizzo, M., Vecera, S.P., 2012. Impaired atten-tional disengagement in older adults with useful field of view decline. Journalsof Gerontology - Series B Psychological Sciences and Social Sciences 67B (4).

[110] J.N., Helmers, K.F., Leveck, M.D., Kleinman, K., 2001. Active: a cognitive intervention trial to promote independence in older adults. Control. Clin. Trials 22 (4), 453-479.

[111] Racette, L., \& Casson, E. J. (2005). The impact of visual field loss on driving performance: Evidence from on-road driving assessments. Optometry and Vision Science, 82(8), 668-674. 